\title{
LUCHA CONTRA EL TERRORISMO INTERNACIONAL: NO SOLO DEL USO DE LA FUERZA PUEDEN VIVIR LOS ESTADOS
}

\author{
Ana SALINAS DE FRÍAS* \\ Catedrática de Derecho internacional público \\ y Relaciones Internacionales \\ Universidad de Málaga
}

SUMARIO: 1. INTRODUCCIÓN.-2. LOS CONVENIOS INTERNACIONALES UNIVERSALES EXISTENTES EN MATERIA DE LUCHA CONTRA EL TERRORISMO: UNA APROXIMACIÓN CLÁSICA QUE CONDICIONA SU EFECTIVIDAD.-2.1. Privilegiando la represión en detrimento de la prevención.-2.2. Obligatoria mejora en los medios de cooperación previstos en los convenios universales.-2.3. El necesario tratamiento preferente de la lucha contra la radicalización ausente en los convenios universales.-3. LA RELATIVA/ABSOLUTA ESTERILIDAD DEL RECURSO SISTEMÁTICO DE LOS ESTADOS A LA FUERZA Y SUS CONSECUENCIAS PARA LOS PILARES BÁSICOS DEL DERECHO INTERNACIONAL.- 4. ¿AL RESCATE DE PROPUESTAS DEL PASADO O DE OPORTUNIDADES PERDIDAS?-5. EL VALOR AÑADIDO DE LA APROXIMACIÓN DESDE LA COOPERACIÓN PENAL INTERNACIONAL.-6. ALGUNAS REFLEXIONES FINALES.

\section{INTRODUCCIÓN}

Los atentados terroristas de septiembre de 2001 contra diversos objetivos en Estados Unidos dejaron patente, si no la muerte de una forma de terrorismo practicada hasta entonces, sí su transformación en un fenómeno residual, igualmente condenable, y el paso a una forma de terrorismo transnacional global nueva no solo en su operativa sino también en su concepción, con nuevas formas de financiación, cada vez más estrechamente ligadas a la criminalidad organizada internacional, y con afán de justificación en una pseudo

* La autora es ex asesora jurídica del Comité de Terrorismo del Consejo de Europa (CODEXTER) y de la Dirección de Asuntos Jurídicos y Derecho Internacional Público de dicha Organización. Es, así mismo, experta independiente para el Consejo de Europa, la OSCE y el Comité Ejecutivo contra el Terrorismo (CTED) de Naciones Unidas (asalinas@uma.es). El presente trabajo se enmarca dentro el Proyecto de investigación DER2015-65486-R, financiado por el Ministerio de Economía y Competitividad. Las opiniones vertidas en el presente artículo son únicamente responsabilidad de la autora. 
guerra de civilizaciones ${ }^{1}$. Es precisamente como consecuencia de algunos aspectos que esta globalización entraña, que la eficacia de los instrumentos convencionales existentes en materia de terrorismo para dar respuesta a esta escalada de violencia se ha visto hoy día muy limitada.

$\mathrm{Al}$ hilo de este tipo de ataques contra la sociedad internacional en su conjunto, y de las respuestas que los mismos provocaron -no siempre acordes con las obligaciones internacionales asumidas por los Estados-, centenares, si no miles de páginas, fueron escritas en las publicaciones científicas más prestigiosas analizando la afección de los pilares básicos del Derecho internacional ${ }^{2}$. La reflexión teórica sobre estos aspectos fue amplia, variada y profunda, y esta misma Revista consagró un número cuasi monográfico ese mismo año específicamente al tema ${ }^{3}$.

Desde aquellos atentados hasta 2016 se han sucedido centenares de ataques terroristas en todo el mundo ${ }^{4}$. Coetáneamente, el Derecho internacional

\footnotetext{
1 Véase al respecto Rehman, J., Islamic State Practices, International Law and the Threat from Terrorism. A Critique of the 'Clash of Civilisations' in the New World Order, Oregón, Hart Publishing, 2005.

2 Obviaremos las violaciones manifiestas del Derecho internacional humanitario ocurridas como consecuencia de la mal llamada "guerra contra el terrorismo» inaugurada por los Estados Unidos de América en respuesta a los ataques terroristas de 2001 en la Declaración hecha por su Presidente George W. Bush el 20 de septiembre de 2001 y que, entre otros elementos, aportó la hasta entonces desconocida, muy criticada y desautorizada categoría de «combatiente ilegal» (véase al respecto, i.a., AвrahaM, G., «Essential Liberty versus Temporary Safety: The Guantanamo Bay Internees and Combatant Status», South African Law Journal, 2004, pp. 121 y ss.; WiLKE, C., "War v. Justice: Terrorism cases, enemy combatants, and political justice in US courts», Politics \& Society, 2004, núms. 33-4, pp. 637-669; SÁNCHEz LEgIDO, A., "Guerra contra el terrorismo, conflictos armados y derechos humanos», en Cursos de Derechos Humanos de Donostia-San Sebastián, Servicio de Publicaciones de la UPV, 2006, pp. 413-470; SALinAS DE FRÍAS, A., "La lucha contra la impunidad en la 'guerra' contra el terrorismo internacional: el derecho a la reparación", en Los Derechos Humanos frente a la impunidad, Cursos de Derechos Humanos de Donostia-San Sebastián, Servicio de Publicaciones de la UPV, 2009, pp. 241-267).

En todo caso, pese al abandono del uso de tal denominación por el Estado creador del mismo y los intentos de su gobierno por cerrar este ominoso capítulo de la acción contra el terrorismo internacional [véase Executive Order: Review and Disposition of Individuals Detained at Guantanamo Bay Naval Base and Closure of Detention Facilities, January 22, 2009, esp. Sec. 3, así como Executive Order Ensuing Lawful Interrogations, en $h t t p s: / / w w w . w h i t e h o u s e . g o v / t h e \_p r e s s \_o f f i c e / C l o s u r e O f G u a n t a n a m o-$ DetentionFacilities (consultada el 12 de junio de 2016)], el penal de Guantánamo subsiste, así como el cautiverio en sus instalaciones de aún ochenta detenidos, en su mayoría yemeníes, a la espera de una mejor solución. Sin duda ello sirvió, en su momento, de caldo de cultivo importante para la radicalización de muchos jóvenes en contextos sociales difíciles o desfavorecidos; no obstante, este hecho constituye hoy día, sin duda, un elemento de menor peso en el conjunto de las nuevas formas y medios de radicalización con fines terroristas.

3 Véase REDI, 2001, núms. 1 y 2, con contribuciones de Alcaide Fernández, Calduch Cervera, Cardona Llorens, Fernández Tomás, gonzález Vega, Ramón Chornet y Remiro Brotóns; pp. 125-302; así como las contribuciones de Pérez GonzÁlez, ANDrés Sáenz de SANTA María y Castillo Daudí acerca de la legítima defensa y la acción del Consejo de Seguridad en la segunda guerra de Iraq en REDI, 2003, núm. 1.

4 En unos casos siguiendo las pautas sentadas en su momento por Al Qaida, y en otras ocasiones siguiendo modelos mixtos con dosis importantes de inspiración propia (Boko Haram, Al Shabab, etc.), pero desde el estallido del conflicto sirio, obedeciendo sobre todo a los dictados de la organización terrorista Estado Islámico. Véase al respecto ANAYA LÓPEZ, V., "Cronología de los atentados terroristas tras los ataques del 11 de septiembre de 2001», en http://www.observatoriodeconflictos.uma.es/ (consultado el 17 de julio de 2016); y https://ourworldindata.org/terrorism/ (consultado el 13 de junio de 2016). Las víctimas de dichos atentados terroristas pertenecientes a Estados árabes, anónimas en muchos
} 
ha trabajado tanto a nivel universal como a nivel regional para proveer a los Estados de instrumentos jurídicos más útiles y contundentes en su lucha contra una lacra escurridiza y camaleónica que ha demostrado una gran capacidad de adaptación para contrarrestar la progresiva eficacia de los medios empleados.

El papel del Derecho internacional para ordenar una cada vez más necesaria y urgente cooperación internacional a nivel político, institucional y, por supuesto, jurídico, se reclama con más fuerza y plantea algunos interrogantes cruciales adicionales a aquellos que se han venido analizando desde 2001: 1) de qué instrumentos jurídicos dispone el ordenamiento internacional en el plano universal para responder a una amenaza que presenta una profunda mutación tanto en su propia concepción como en los medios de comisión material y qué eficacia tienen estos; 2) la esterilidad del recurso sistemático de los Estados al uso de la fuerza de forma unilateral o incluso multilateral, pero con dudoso respeto de los límites establecidos por el ordenamiento jurídico internacional; 3) el discutible rescate de alguna propuesta histórica como solución al actual estado de cosas; 4) qué podría añadir a esta lucha un mejor y más exhaustivo uso de los instrumentos que articulan la cooperación penal internacional y la lucha contra la criminalidad organizada y otras actividades ilícitas internacionales.

\section{LOS CONVENIOS INTERNACIONALES UNIVERSALES EXISTENTES EN MATERIA DE LUCHA CONTRA EL TERRORISMO: UNA APROXIMACIÓN CLÁSICA QUE CONDICIONA SU EFECTIVIDAD}

Resulta una convicción ampliamente extendida que de la misma forma que Al Qaida obtuvo su consagración mundial como grupo terrorista líder tras los ataques del 11/S y que controló durante años el mapa de ataques de este cuño a nivel mundial, sucediéndose estos en paralelo a las ocupaciones de Iraq y de Afganistán, el Daesh ha logrado no solo sustituir en el liderazgo mundial a dicha asociación criminal, retroalimentándose también en este caso de un conflicto armado como el de Siria y los vacíos de poder creados por este ${ }^{5}$, sino incluso superarla con creces, en la medida en que ha consegui-

\footnotetext{
casos e ignoradas en buena medida por los países occidentales, superan, por cierto, por cientos a las europeo-occidentales.

${ }_{5}$ Véase el retrato ofrecido por REmiro BRotons en relación a la situación de Afganistán en los meses previos a los atentados del 11 de septiembre de 2001 (REMIRo Brotons, A., «Terrorismo, mantenimiento de la paz y nuevo orden», REDI, 2001, núms. 1 y 2, pp. 125 y ss., y en particular pp. 140-150), así como el Informe del Secretario General de UN sobre la situación en Afganistán y sus consecuencias para la paz y la seguridad internacionales, Doc. A/55/1028-S/2001/789. En relación al conflicto sirio y el ascenso del Daesh véase, entre otros, MARTín, J., Estado Islámico. Geopolítica del caos, Catarata, 2015. De igual forma ha de observarse la insistencia de NU sobre la relación entre ese y otros conflictos armados y el triunfo del terrorismo, y en particular del Daesh, afirmada en las Resoluciones del Consejo de Seguridad S/RES/1377 (2001), de 12 de noviembre de 2001; S/RES/1456 (2003), de 20 de enero de 2003; S/RES/1566 (2004), de 8 de octubre de 2004; Informe del Secretario General de UN sobre la ame-
} 
do una base territorial propia en absoluto desdeñable ${ }^{6} \mathrm{y}$ en la que ha desplegado una estricta y jerarquizada organización política emulando a un Estado moderno obviamente no democrático ${ }^{7}$; se ha dotado de una población propia recurriendo incluso a tácticas que podrían considerarse como genocidas respecto de las eliminación en el territorio bajo su control o «territorio del Estado» ciertas minorías religiosas como la yazidí8; y se ha dotado de fuentes de financiación propias e independientes en estrecha colaboración con viejas y nuevas formas de criminalidad organizada transnacional ${ }^{9}$.

Además, el despliegue de medios técnicos del que ha hecho gala esta asociación criminal para su propaganda y su experto uso de las nuevas tecnologías de la comunicación y la información (TICs) han contribuido no solo a su fortalecimiento y estabilización, sino a multiplicar el reclutamiento de terroristas. Con la llamada a la yihad global ${ }^{10}$, fenómenos como el reclutamiento pasivo, el autoadiestramiento o autorradicalización, así como la aparición de los llamados foreign terrorist fighters, han hecho que en toda estrategia política o jurídico-legal antiterrorista la lucha contra la radicalización y sus causas se haya convertido en un objetivo prioritario a tratar.

Pero lo cierto es que los tratados internacionales universales existentes actualmente en materia de lucha contra el terrorismo ${ }^{11}$ presentan de forma

naza que plantea el EIIL (Daesh) para la paz y la seguridad internacionales y la gama de actividades que realizan las NU en apoyo de los Estados miembros para combatir la amenaza, S/2016/92, de 29 de enero de 2016.

6 La superficie controlada por esta organización terrorista ha llegado a alcanzar los 200.000 km cuadrados, una extensión casi equivalente a la del Reino Unido [véase artículo de CockBURN, P., «War against the Islamic State, The Independent, 20/11/2014», en http://www.rebelion.org/noticia. php? id=192218 (consultado el 13 de junio de 2016)], aunque en la actualidad se encuentra mucho más reducido en virtud de la acción de la coalición internacional liderada por Estados Unidos que combate a esta organización terrorista (sobre la composición de la coalición véase la información actualizada del Departamento de Estado de Estados Unidos en http://www.state.gov/s/seci/). Véase igualmente COCKBuRn, P., ISIS, el Retorno de la Yijad, Ariel, 2014.

7 Véase Hénin, N., Jihad Academy. Nos erreurs face à l'État islamique, Fayard, 2015. En cuanto a cómo gobierna el grupo yihadista Estado Islámico, véase: http://www.bbc.com/mundo/noticias/2014/09/140908_estado_islamico_gobierno_nc (consultado el 13 de junio de 2016); IBAYAT, A., "Islam and Democracy: What is the Real Question?», ISIM Papers, 2007, núm. 8; Napoleoni, L., El Fénix Islamista. El Estado Islámico y el Rediseño de Oriente Próximo, Paidós, 2015.

8 Véase Esparza, J., Historia de la Yihad, Catorce siglos de sangre en el nombre de Alá, La esfera de los libros, 2015.

9 Así, por ejemplo, el secuestro, la extorsión, el contrabando, el tráfico de diversos elementos prohibidos por el Derecho internacional (sustancias prohibidas desde el punto de vista de la seguridad y fabricación de armamento y explosivos como desde el punto de vista de la salud pública, personas, armas, petróleo), pero también de otras modernas como el expolio sistemático y la destrucción o, en caso de ser posible, la venta de obras de arte y patrimonio cultural protegido.

10 Acerca del concepto de yihad y su uso belicista interesado desde las facciones más extremistas de la religión islámica véase el trabajo de Gutiérrez EsPADA, C., «Radicales y reformistas en el Islam (sobre el uso de la violencia)», REDI, 2009, núm. 1, pp. 13 y ss.

11 Convenio sobre las aeronaves y ciertos otros actos cometidos a bordo de las aeronaves (Convenio de Tokio, 1963; 185 Estados partes); Convenio para la represión del apoderamiento ilícito de aeronaves (Convenio de La Haya, 1970; 185 Estados partes) y Protocolo adicional de Beijing de 2010, aún no en vigor (siete Estados ratificantes); Convenio para la represión de actos ilícitos contra la seguridad de la aviación civil (Convenio de Montreal, 1971; 185 Estados partes) y su Protocolo adicional sobre la seguridad de los aeropuertos, de 1988 (171 Estados partes); Convención para la prevención y el castigo 
sistemática varias limitaciones que constituyen, en nuestra opinión, un freno en su efectividad a día de hoy ${ }^{12}$.

\subsection{Privilegiando la represión en detrimento de la prevención}

La primera de las circunstancias que frenan la eficacia de los convenios universales en materia de terrorismo deviene del hecho de que estos pongan el acento en la represión del terrorismo - lo que significa una acción expost - en lugar de en la prevención, haciendo escasa o nula referencia a las causas profundas conducentes al terrorismo internacional.

Si en un principio los convenios en cuestión prácticamente no hacían mención al contexto o las causas conducentes al terrorismo internacional, dado también lo escueto de los textos y lo técnico del tratamiento de estas situaciones, en cambio sí se incluyó una cierta relación entre las ofensas terroristas y las relaciones pacíficas y cooperativas entre las naciones y los principios de la Carta de las (NU) en algunos convenios posteriores, de donde cabe deducir que a partir de aquí el objetivo genérico perseguido por estos tratados fue más amplio, incluyendo también la lucha por la erradicación de las causas subyacentes al terrorismo internacional.

Sin embargo, es muy revelador que esta referencia haya desaparecido a medida que el fenómeno terrorista se ha globalizado. Así, el Convenio para la represión de los atentados terroristas cometidos con bombas ${ }^{13}$ ha obviado toda mención a otro tipo de medidas de acompañamiento, como también lo ha hecho el Convenio para la represión de la financiación del terrorismo ${ }^{14}$; el

de delitos contra personas internacionalmente protegidas, 1973 (172 Estados partes); Convención internacional contra la toma de rehenes, 1979 (167 Estados partes); Convención sobre la protección física de los materiales nucleares, 1980 (142 Estados partes) y Protocolo de enmienda de 2005 (42 Estados partes); Convenio para la represión de actos ilícitos contra la seguridad de la navegación marítima, 1988; (156 Estados partes) y su Protocolo adicional de 2005 (17 Estados partes); Protocolo para la represión de actos ilícitos contra la seguridad de las plataformas fijas emplazadas en la plataforma continental, de 1988 (144 Estados partes) y su «Protocolo» adicional de 2005 (12 Estados partes); Convenio internacional sobre la marcación de explosivos plásticos para los fines de detección, de 1988 (144 Estados partes); Convenio internacional para la represión de atentados terroristas cometidos con bombas, de 1977 (164 Estados partes); Convenio internacional para la represión de la financiación del terrorismo, de 1999 (173 Estados partes); Convenio internacional para la represión de los actos de terrorismo nuclear, de 2005 (71 Estados partes). Véanse todos los Convenios de NU en materia de lucha contra el terrorismo en http://www.un.org/en/sc/ctc/laws.html (consultado del 12 de junio de 2016). Sobre la cronología de estos, su agrupación por materias, y los acontecimientos y atentados que finalmente propiciaron su adopción véase SALINAS DE FRÍAS, A., «La práctica convencional multilateral de los Estados en materia de cooperación judicial internacional contra el terrorismo», Anuario Argentino de Derecho Internacional, 2006, pp. 69-105.

12 Solo en el ámbito regional pueden observarse honrosas excepciones. Véanse, en este sentido, los siguientes convenios: OUA Convention on the Prevention and Combating of Terrorism, adoptada en Argelia el 14 de julio de 1999, y en vigor desde el 06 de diciembre de 2002; Council of Europe Convention on the Prevention on Terrorism, adoptada en Varsovia, el 16 de mayo de 2005, y su Protocolo adicional, adoptado en Riga el 20 de octubre de 2016.

13 Véase texto en $B O E$ núm. 140, de 12 de junio de 2001.

14 Véase texto en BOE núm. 123, de 23 de mayo de 2002. 
Convenio para la represión de los actos de terrorismo nuclear ${ }^{15}$; o el citado Protocolo de Beijin de 2010, que ni en su breve Preámbulo ni en su articulado contiene referencia parecida alguna ${ }^{16}$. Y ello a pesar de que la AGNU haya establecido expresamente como el primero de sus pilares básicos en la acción contra este en su Estrategia Global contra el Terrorismo desde 2006 hasta nuestros días las «Medidas para hacer frente a las condiciones que propician la propagación del terrorismo» ${ }^{17}$.

Este tratamiento del problema obviando cualquier mención en este sentido es significativo y no parecería justificarse más que, si acaso y dudosamente, por el hecho de que los recientes atentados terroristas, de una gravedad y magnitud desconocida anteriormente, hayan sido reivindicados por otro tipo de grupos terroristas que nada tienen que ver con toda lucha de liberación nacional o colonial ${ }^{18}$, lo que en todo caso no es óbice para su desaparición, pues mucho tiene ello que ver con el creciente fenómeno de radicalización terrorista que se vive a nivel mundial.

Lo extraño no es solo la ausencia en sí en estos convenios, sino el mismo silencio al respecto en instrumentos posteriores a los ataques del $11 / \mathrm{S}^{19}$, cuando no solo se ha globalizado el fenómeno terrorista, sino que el propio Consejo de Seguridad de Naciones Unidas (CSNU) ha actuado ya de forma sistemática, desde el establecimiento del «emirato» por los talibanes en parte

15 Véase texto en BOE núm. 146, de 19 de junio de 2007.

16 Ratificado por cierto tan solo por Países Bajos, República Checa y Suiza entre los países desarrollados, y firmado hasta ahora adicionalmente solo por Australia, España, Estados Unidos, Francia y Reino Unido. Véase: http://www.icao.int/secretariat/legal/List\%20of\%20Parties/Beijing_Prot_ES.pdf (consultado el 3 de junio de 2016). El art. 1.f), establece que: «Any person commits an offence if that person unlawfully and intentionally: (...) (f) uses an aircraft in service for the purpose of causing death, serious bodily injury, or serious damage to property or the environment (...)».

17 Véase Resolución de la AGNU A/RES/60/288, de 28 de septiembre de 2006, estableciendo la Estrategia global de las NU contra el terrorismo, y que se articula en cuatro pilares básicos: I. Medidas para hacer frente a las condiciones que propician la propagación del terrorismo; II. Medidas para prevenir y combatir el terrorismo; III. Medidas destinadas a aumentar la capacidad de los Estados para prevenir el terrorismo y luchar contra él, y a fortalecer el papel del sistema de las NU a ese respecto; y IV. Medidas para asegurar el respeto de los derechos humanos para todos y el imperio de la ley como base fundamental de la lucha contra el terrorismo. La estrategia ha sido revisada por última vez junio de 2014, manteniendo la misma estructura con los mismos pilares aunque actualizando esta e insistiendo en la acción contra nuevas formas de terrorismo o de conductas conexas y cómo abordarlas, recordando, por ejemplo, en el uso de aviones no tripulados y los efectos colaterales adversos que estos puedan tener, la radicalización y el auto adiestramiento, el uso de la nuevas tecnologías y redes sociales y la acción terrorista individualizada por los conocidos como «lobos solitarios», así como la adopción de mecanismos eficaces para luchar contra el reclutamiento de combatientes extranjeros como consecuencia del llamamiento generalizado a la yihad a nivel mundial. Véase A/RES/68/276, relativa al Examen de la Estrategia Global de las NU contra el Terrorismo, aprobada por la AGNU el 13 de junio de 2014.

18 Y ello a pesar del uso interesado del Daesh en su proclamación del Califato en 2014 de su impugnación de los acuerdos Sykes-Picot como base de su acción armada por la recuperación y reunificación de un territorio, oportunista por lo demás y esgrimida tal vez a efectos de dotarse de algún tipo legitimidad. Véase este elemento en el momento de la proclamación del Califato en http://www.europapress. es/internacional/noticia-isis-proclama-califato-islamico-nombra-califa-baghdadi-20140629202653.htlm (consultado el 2 de junio de 2016).

${ }_{19}$ Véase, por ejemplo, en el Convenio para la represión de los actos de terrorismo nuclear, de 2005, que obvia cualquier otro tipo de medidas de acompañamiento más allá de la pura represión. 
del territorio afgano y la amenaza que ello suponía, basándose en el Capítulo VII de la Carta de UN, estableciendo a partir de entonces una relación directa entre el terrorismo y el mantenimiento de la paz y la seguridad internacionales ${ }^{20}$.

\subsection{Obligatoria mejora de los medios de cooperación previstos en los convenios universales}

La segunda circunstancia a tomar en cuenta, y resultado directo del reiterado fracaso de las soluciones puramente represivas, es la necesidad de una cada vez mayor cooperación entre los Estados en esta materia que se constata por la globalización del fenómeno terrorista ${ }^{21}$. Evidentemente esta puede alcanzar formas muy especializadas en caso de convenios altamente técnicos donde las conductas a combatir son especialmente complejas, como es el caso del Convenio para la represión de la financiación del terrorismo o el Convenio para la represión de actos de terrorismo nuclear. En cualquier caso, hay un núcleo de acciones represivas cooperativas entre las partes contratantes perfectamente identificado y consolidado, y que básicamente obligan a la armonización en la tipificación nacional de las conductas consideradas terroristas, el establecimiento de una jurisdicción amplia, un reforzamiento especial del mecanismo de la extradición y una reafirmación de la asistencia judicial en sentido amplio entre los Estados ${ }^{22}$. Puesto que el establecimiento de jurisdicción no es suficiente a fines del enjuiciamiento en los ordenamientos jurídicos internos, los convenios de ámbito universal exigen desde el primer momento la inclusión (tipificación) de las conductas listadas en ellos en los sistemas penales nacionales ${ }^{23}$, así como el establecimiento de sanciones y penas suficientemente graves y disuasorias, y el necesario enjuiciamiento con base en criterios de jurisdicción progresivamente más amplios.

Las deficiencias más significativas que se desprenden de esta forma habitual de proceder serían, en primer lugar, que los medios de cooperación previstos se centran casi exclusivamente en conductas terroristas consumadas,

${ }^{20}$ A excepción de la mención hecha por el CSNU en varias resoluciones en relación con el caso Lockerbie. Véase REMIRo BROTONS, op. cit., nota 5, p. 131 y bibliografía citada al respecto de la doctrina española. Véanse también, a este particular respecto, resoluciones del CSNU S/RES/1373(2001); S/ RES/1566(2004); S/RES/2178(2014); S/RES/2199(2015); S/RES/2253(2015); S/RES/2255(2015).

21 Ya apuntadas por REMIRo BROTONs, op. cit., nota 5, p. 170, y por FERNÁNDEZ ToMÁs, A., «El recurso al artículo quinto del Tratado de Washington tras los acontecimientos del 11 de septiembre: mucho ruido y pocas nueces», REDI, 2001, núms. 1 y 2, pp. 205 y ss., y en particular p. 210.

22 En el mismo sentido véase Alcaide FernánDEZ, J., «La "guerra contra el terrorismo": ¿una “OPA hostil” al Derecho de la comunidad internacional?», REDI, 2001, núms. 1 y 2, pp. 289 y ss., en particular pp. 290-91.

${ }^{23}$ Lo que se solicita de forma menos explícita en un principio y más taxativa e incluso vehemente después. Véase dicha evolución respecto de la contundencia de las medidas en las siguientes disposiciones: art. 2 del Convenio para la represión de la financiación del terrorismo; art. 3 del Convenio de Montreal; art. 2 del Convenio sobre la toma de rehenes; art. 3 del Convenio para la represión de los atentados terroristas cometidos con bombas, art. 4 para la represión de la financiación del terrorismo y art. 5 del Convenio para la represión de los actos de terrorismo nuclear. 
privilegiando y facilitando en lo posible la extradición, obviando la necesidad de contar con un convenio previo específico de extradición entre las partes afectadas y considerando dichos tratados como base suficiente para proceder a la misma. Además, se pasa en ellos de la obligación genérica de extraditar o juzgar a la obligación concreta de todo Estado contratante en cuyo territorio se encuentre el presunto autor de la ofensa terrorista de detener al mismo o tomar las medidas necesarias para asegurar su presencia a efectos de procesamiento penal o extradición, lo que deberá ser puesto inmediatamente en conocimiento del Secretario General de UN, que lo comunicará, a su vez, al resto de las partes en el Convenio.

Esto es, en los convenios universales, a diferencia de la acción contra el terrorismo en el ámbito regional, la extradición supone el medio de cooperación preferente y casi único entre las partes contratantes ${ }^{24}$. Sin embargo, a nivel regional existen una serie de convenios específicos de asistencia judicial en materia penal en sentido amplio que, sin dejar de lado el respeto de las garantías necesarias - en particular las procesales- de aquellos afectados, tanto por la extradición como por otros mecanismos de asistencia judicial, plantean iniciativas conjuntas de extrema utilidad ${ }^{25}$.

En segundo lugar, estos convenios sugieren un enfoque clásico en materia de cooperación internacional caracterizado por dos elementos básicos: la inclusión de un listado de acciones a tipificar como ofensas terroristas en los Estados partes, y la rotunda exclusión del delito político, precisando así las obligaciones de los Estados partes al respecto que se resumen en penalizar, juzgar y, en caso contrario, extraditar (Aut prosequit aut dedere), dada la falta de un acuerdo internacional en una definición común de terrorismo ${ }^{26}$ que tiene paralizados los trabajos en VI Comisión de la AGNU a fin de con-

24 Excepción hecha de ciertas previsiones de acompañamiento en algunos convenios en relación con el respeto del art. 36 del Convenio de Viena sobre Relaciones Consulares y de la posibilidad de que el Estado que ejerza la jurisdicción invite al CICR a ponerse en contacto o entrevistarse con la persona presuntamente responsable de una conducta terrorista.

${ }_{25}$ Tal es el caso de los siguientes convenios del Consejo de Europa: Convenio sobre asistencia mutua en materia penal, ETS núm. 30; el Protocolo Adicional al mismo, ETS núm. 99; el Segundo Protocolo Adicional, ETS núm. 182; Convenio sobre la transmisión de procedimientos penales, ETS núm. 73; el Convenio sobre el blanqueo, seguimiento, embargo y confiscación de los productos del crimen, ETS núm. 141; o el Convenio sobre traslado de personas condenadas, ETS núm. 112 y su Protocolo Adicional, ETS núm. 167. O en el ámbito de la OEA la Convención interamericana sobre asistencia mutua en materia penal (A-55), de 1992; y su Protocolo Facultativo (A-59), de 1993. En ellos se plantea, i.a., la creación de equipos conjuntos de investigación no solo entre Estados partes en los convenios, sino también con terceros Estados que así lo deseen y que tan útiles están siendo en Europa a la hora de investigar estos crímenes.

${ }_{26}$ Como ya sucediera en época de la Sociedad de Naciones en las Convenciones de 1937 para la prevención y la represión del terrorismo, de 16 de noviembre de 1937, y la Convención para la creación de una Corte Penal Internacional, surgidos en respuesta al asesinato del rey Alejandro de Yugoslavia y del ministro de Asuntos Exteriores francés Barthou el 9 de octubre de 1934, y en particular debido a la negativa del gobierno italiano de extraditar a los culpables. Ambas convenciones, que nunca llegaron a entrar en vigor, resultaron sin embargo determinantes con posterioridad en la forma en la que se abordó el terrorismo desde el punto de vista convencional ya en época de NU, en la medida en que los elementos fundamentales que se utilizan en ambos convenios han tenido claro reflejo en los posteriores convenios sectoriales adoptados en el seno de NU. Acerca de aquellos, véase: DonNEDIEU DE VABRES, H., 
cluir un acuerdo omnicomprensivo y con alcance universal de lucha contra el terrorismo ${ }^{27}$. Por tanto, estos convenios se centran en la fórmula del listing, enunciando cada una de las conductas consideradas como terroristas, y definiendo solo de forma sectorial, parcelada e indirecta el terrorismo en sí, mediante un listado vivo que se completa y actualiza continuamente.

Pero lo cierto es que este enfoque no acaba de ofrecer mecanismos eficaces de lucha contra un modelo de terrorismo diferente a aquel para el que fueron concebidos. Así, en ese listado acumulativo se echa manifiestamente en falta, por ejemplo, la inclusión de actos preparatorios previos necesarios para la culminación de un ataque terrorista, tales como el reclutamiento, el entrenamiento o la incitación pública (apología) a cometer actos terroris$\operatorname{tas}^{28}$. Además, resulta que, si bien muchos de los antiguos modos de comisión siguen siendo utilizados por el nuevo terrorismo del siglo XXI, en especial por el terrorismo yihadista ${ }^{29}$, lo cierto es que los modos de comisión reiteradamente utilizados por este nuevo terrorismo en ocasiones poco o nada tienen que ver con los previstos en dichos convenios, en particular en aquello que hace a las nuevas formas de reclutamiento pasivo, la radicalización y los nuevos modos de financiación.

\footnotetext{
«La répresion internationale du terrorisme. Les Conventions de Génève (16 novembre 1937)», Revue de Droit International et de Législation Comparée, 1938, pp. 37-74.

27 La Resolución de la AGNU 51/210, de 17 de diciembre de 1996, estableció un Comité Ad Hoc encargado de negociar y acordar los términos de un Convenio omnicomprensivo en materia de lucha contra el terrorismo que, sin embargo, permanece bloqueado ante el desacuerdo de dos bloques de países en cuanto a la definición de terrorismo, no tanto en los comportamientos comprendidos dentro de este término, sino en cuanto a quiénes pueden perpetrarlos, no estando clara la diferencia entre aquellos actos cometidos por las fuerzas armadas de un Estado y por los llamados movimientos de liberación nacional, o lo que es lo mismo, terrorismo de Estado versus derecho de autodeterminación de los pueblos. Véase, al respecto, KLEIN, P., Le droit international à la épreuve du terrorisme, 321 RCADI (2006), pp. 203 y ss., en particular pp. 242-243. Y en la doctrina española JiménEz GARcía, F., «Derecho Internacional Penal y Terrorismo. Historia de una relación incapaz de materializarse estatutariamente», en https://www.google.es/search?q=Derecho+internacional+penal+y+terrorismo+Francisco+Jimene $z \& i e=u t f-8 \& o e=u t f-8 \&$ client $=$ firefox $x \& g f e \_r d=c r \& e i=A w 6 T V 570 G q 6 x 8$ wewyImgCg (última consulta 18 de junio de 2016).

28 Paliado solo por iniciativas regionales convencionales, como es el caso del Convenio del Consejo de Europa de Prevención del Terrorismo, ETS núm. 196, de 16 de mayo 2005, y no convencionales, como la Decisión Marco 2008/919/JAI del Consejo de la UE, DOUE L de 9 de diciembre de 2008, modificando la Decisión marco previa del Consejo en materia de terrorismo de 2002 (2002/475/JAI, DOUE L 164, de 22 de junio de 2002). Sobre la génesis del Convenio véase BENítez, R. A., «Un nuevo convenio anti-terrorista para Europa, 7 reei (2003)», en http://www.reei.org/index.php/revista/num7/articulos/ nuevo-convenio-anti-terrorista-para-europa (consultada el 13 de junio de 2016); HunT. A., «The Council of Europe Convention on the Prevention of Terrorism», European Public Law , 2006-4, pp. 603 y ss.; Kolb, M.: The European Union and the Council of Europe, Viena, Palgrave McMillan, 2013, pp. 87 y ss.; SALINAS DE FRÍAS, A., "La obra convencional del Consejo de Europa en la prevención y lucha contra el terrorismo internacional», Anuario de Derecho Internacional, 2009, pp. 435 y ss., p. 453. Véase igualmente el Convenio de la OUA: OAU Convention on the Prevention and Combating of Terrorism, de 1 de julio de 1999, en http://www.au.int/en/treaties/oau-convention-prevention-and-combating-terrorism, y comentario de Solomon, H., Responding to Terror: An Assessment of the African Union Counter-Terrorism Strategies, Palgrave Macmillan, 2015.

${ }_{29}$ Como es el caso de los atentados contra la seguridad de la navegación aérea del que la explosión en vuelo del avión ruso en Sharm El Sheikk, Egipto, hace menos de un año, con la cifra de 224 víctimas y reivindicado por el Daesh en 2015, es un triste ejemplo.
} 
Ello revela no solo la insuficiencia de la regulación universal existente, sino también nuevos problemas en el ejercicio de la cooperación internacional tradicionalmente prevista a estos efectos, en particular respecto del terrorismo islámico. Y pese al eco que de esta preocupación se han hecho tanto la AGNU como el propio CSNU, no parece que a corto plazo se vayan a explorar soluciones universales eficaces más allá de lo hasta aquí conseguido ${ }^{30}$.

Especialmente significativo resulta al respecto la falta de acción ante la contundente petición de NU a los Estados de cooperar para frenar el fenómeno del reclutamiento de combatientes extranjeros que alimenta las filas del Daesh $^{31}$, fenómeno íntimamente ligado a la radicalización, y que de momento solo ha recibido respuesta a nivel regional ${ }^{32}$, pero no universal. Del mismo modo cabe destacar la falta de acción de los Estados en relación con la preocupación manifestada también por la Organización internacional respecto de ciertos modos y medios utilizados para combatir al terrorismo y su compatibilidad con ciertos principios básicos del ordenamiento internacional ${ }^{33}$, o del estancamiento de ciertos conflictos armados que alimentan el crecimiento de la militancia en ciertos grupos terroristas como es el caso del conflicto sirio y el Daesh ${ }^{34}$, lo que nos conduce al siguiente punto.

\subsection{El necesario tratamiento preferente de la lucha contra la radicalización ausente en los convenios universales}

La tercera circunstancia la constituye sin duda la ausencia de mención del fenómeno de la radicalización y su innegable influencia sobre el actual terrorismo internacional. Y es que durante mucho tiempo se entendió que

\footnotetext{
30 Acerca de la naturaleza excepcionalmente peligrosa del grupo terrorista Daesh y de su consideración como amenaza sin precedentes véase el preámbulo de la Resolución S/RES/2249 (2015); Informe del Secretario General sobre la amenaza que plantea el EIIL (Daesh) para la paz y la seguridad internacionales y la gama de actividades que realizan las Naciones Unidas en apoyo de los Estados miembros para combatir la amenaza, de 29 de enero de 2016, S/2016/92 (en particular parr. 13), realizado en cumplimiento de la Resolución UNSC 2253(2015) de 17 de diciembre de 2015, parr. 97, e igualmente Informe del Secretario General sobre la amenaza que plantea el EIIL (Daesh) para la paz y la seguridad internacionales y la gama de actividades que realizan las Naciones Unidas en apoyo de los Estados miembros para combatir la amenaza, S/2016/501, de 31 de mayo de 2016, parr. 7.

31 Véanse Resoluciones del Consejo de Seguridad S/RES/2170(2014), de 15 de agosto de 2014 y, en particular, S/RES/2178(2014), de 24 de septiembre de 2014.

32 Véase al respecto el Protocolo adicional a la Convención de Prevención del Terrorismo del Consejo de Europa, ETS núm. 217, de 22 de octubre de 2015.

33 Véase al respecto la Resolución de la AGNU A/RES/68/276, que específicamente: «Insta a los Estados miembros a que se aseguren, al adoptar cualquier medida o utilizar cualquier medio contra el terrorismo, incluido el uso de aeronaves teledirigidas, de cumplir las obligaciones que les incumben en virtud del Derecho internacional [...] en particular los principios de distinción y proporcionalidad». Resolución 68/276, de 13 de junio de 2014, sobre el Examen de la Estrategia Global de las NU contra el Terrorismo, parr. 13. Véase GómEz ISA, F., «Los ataques armados con drones en Derecho internacional», REDI, 2015, núm. 1, pp. 61-92.

34 Véanse, entre otras, las resoluciones del CSNU S/RES/1377 (2001), de 12 de noviembre de 2001; S/RES/1456 (2003), de 20 de enero de 2003; S/RES/1566 (2004), de 8 de octubre de 2004; y S/ RES/2249(2015).
} 
tal mención podría suponer una justificación del mismo. Dada la naturaleza del actual terrorismo internacional, no solo los sucesivos relatores especiales de NU en materia de lucha contra el terrorismo y protección simultánea de los derechos humanos han desautorizado esta visión, pues nada impide que una investigación científica seria en las causas de la radicalización terrorista pueda ir acompañada de una clara repulsa de dichas acciones ${ }^{35}$, sino que los Estados a título individual han expuesto su preocupación por la forma en que las narrativas extremistas de corte político y religioso elaboradas por organizaciones terroristas y simpatizantes, en particular en el caso del terrorismo nacido del fundamentalismo islámico, pueden ser contrarrestadas, considerando esta tarea de importancia crítica ${ }^{36}$. Este enfoque guarda además una estrecha relación con las causas profundas del terrorismo internacional, mal o escasamente tratadas en dichos instrumentos convencionales internacionales como se ha visto, y que mucho tienen que ver con el incumplimiento por parte de los Estados, entre otras, de las obligaciones asumidas en virtud de su participación en tratados de derechos humanos de protección de derechos humanos en general, y de derechos económicos, sociales y culturales en particular ${ }^{37}$.

35 Véase ScheinIn, M., First Report, Doc. E/CN.4/2006/98, 205, p. 20, parr. 65.

36 Resulta llamativa la posición actual de especialistas en el Reino Unido a este respecto, por la tendencia de dicho país a posiciones opuestas en el pasado, situando el estudio y la búsqueda de soluciones a la radicalización en el centro de la lucha contra el terrorismo, lo que supone un cambio de paradigma importante, no solo al pasar de la preocupación por la represión a la preocupación también por la prevención, sino incluso por adoptar una perspectiva no estrictamente securitaria sino que toma en cuenta adicionalmente el contexto sociológico y económico. Véase al respecto, entre otras muchas, Stainforth, A., Preventing Terrorism and Violent Extremism, Oxford, Oxford University Press, 2014; NORWEGIAN MINISTRY OF JUSTICE AND PUBLIC SECURITY, Action Plan against Radicalisation and Violent Extremism, p. 23 y ss.; INSTITUTE FOR STRATEGIC DIALOGUE, European Counter-Radicalisation and De-radicalisation: A Comparative Evaluation of Approaches in the Netherlands, Sweden, Denmark and Germany, 2005; Council of Europe Action Plan to combat extremism and radicalization leading to terrorism, SG/Inf(2015)11 Rev., en particular p. 6. Véase igualmente AwAN, I. y BlaKEMORE, B. (eds.), Extremism, Counter-Terrorism and Policing, Ashgate, 2013.

37 Además de las referencias genéricas al respecto que tanto la AGNU como el CSNU vienen haciendo de forma sistemática en sus resoluciones desde 2001, y en particular desde la adopción por parte de la AGNU de la Estrategia Global contra el Terrorismo, otras instancias de esta organización han insistido también en la relación directa entre la protección, promoción y mejora de los derechos económicos, sociales y culturales de ciertas poblaciones y la eficacia de la lucha contra el terrorismo. Destacan al respecto, además de las ya mencionadas afirmaciones del Relator especial en la materia M. Scheinin (también en relación con la discriminación en el disfrute de dichos derechos y el riesgo de radicalización: Doc. A/HRC/4/26, de 29 de enero de 2007, parrs. 38, 40 y 49), las realizadas en el mismo sentido por el Comité de Derechos Económicos, Sociales y Culturales de UN en su Observación General núm. 20, Doc. E/C.12/GC/20, de 2 de julio de 2009, sobre «La no discriminación y los derechos económicos, sociales y culturales»; y en su Observación General núm. 21, Doc. E/C.12/GC/21, de 21 de diciembre de 2009, sobre el «Derecho de toda persona a participar en la vida cultural», en particular parrs. 32-35, relativos a las minorías y los inmigrantes; o por el Consejo de Derechos Humanos de NU, Resolución 7/7, de 27 de marzo de 2008, parrs. 6,7; Resolución 10/15, de 26 de marzo de 2009, parr. 6; y Resolución 13/26, de 15 de abril de 2010, parrs. 5-6.

Especialmente significativo al respecto son las afirmaciones de la CIJ en su opinión consultiva acerca de las consecuencias de la construcción de un muro en los territorios palestinos ocupados, relativas a que la forma en que las autoridades israelíes ejercen su control sobre los pasos a lo largo del muro afecta negativamente al acceso de estos a la educación, al impedir en muchas ocasiones el acceso de los niños palestinos a las instituciones educativas o la movilidad de los profesores; a los servicios 
Y es que sean cuales fueren las causas profundas que muevan los resortes internos de la persona para caer en la radicalización, y en otro orden de consideraciones, lo cierto es que sus posibilidades de materialización se han visto magnificadas en confluencia con las TICs. Tal vez por eso deba valorarse muy positivamente su concreción en el ámbito europeo, que se ha producido mediante un instrumento singular, el Protocolo Adicional a la Convención sobre Cibercriminalidad ${ }^{38}$ relativo a la penalización de actos de naturaleza racista o xenófoba perpetrados mediante sistemas informáticos ${ }^{39}$. El convenio se ciñe, conforme a los propósitos establecidos en su art. 1, a las definiciones ofrecidas en su art. 2, a la obligación de criminalización de la difusión, distribución o cualquier otra forma de puesta a disposición pública mediante sistemas informáticos, de material escrito, imágenes, representaciones en sentido amplio de ideas o teorías que defiendan, promuevan o inciten al odio, la discriminación o la violencia contra personas individual o colectivamente consideradas, basadas en la raza, color, descendencia u origen étnico o nacional o la religión. Este instrumento podría ser especialmente útil no solo para combatir el terrorismo yihadista, sino también el practicado por otros individuos de ideología extremista ${ }^{40}$. Y aún en el actual escenario de terrorismo yihadista, donde la invitación a la guerra santa no deja de ser una llamada al odio generalizado a todo aquel que no pertenezca a esa forma extrema de

de salud, así como otros servicios sociales y el acceso al desarrollo de su actividad laboral cuando esta depende del paso al otro lado del muro. El resultado que todo ello ha provocado ha sido un efecto socioeconómico devastador en estas comunidades (véanse parrs. 130-134).

Y aún más significativos al respecto resultan los detallados datos ofrecidos al respecto por el Relator especial Scheinin en su Informe relativo a su visita a los territorios palestinos ocupados, en el que resalta, entre otros muchos elementos, el hecho de que la forma en que las autoridades israelíes ejercen su control sobre los pasos a lo largo del muro afecta negativamente al acceso de las mujeres a los servicios de salud, incluidos los servicios de urgencia, donde destacan los partos habidos en los check-points sin asistencia médica, con serios riesgos para las madres y los nacidos y con la muerte de un número significativo de mujeres como consecuencia de las largas colas de espera para atravesar los puntos de control y de la falta de asistencia médica en tales momentos; así como el acceso ordinario de los palestinos a sus tierras de cultivo, impidiéndoles el uso o traslado de maquinaria pesada, la contratación de peones para trabajar las tierras, o la obstaculización sistemática del acceso al agua, todas ellas razones por las cuales muchas tierras de cultivo, que constituían el soporte económico de una o varias familias, han sido abandonadas. Véase Informe del Relator especial Scheinin, Doc. A/HCR/6/17/ Add.4), que concluye afirmando que «[...] the barrier and its associates effects continue to cause violation of economic, social and cultural rights, and that it is experienced by Palestinians as unlawful, destructive to normal human life, and humiliating [...]» y que, por tanto, "[...] as a consequence, we must consider that the barrier has a counterproductive effect by contributing to conditions that are conducive to the recruitment to and the spread of terrorism [...]» (véase parr. 43 del documento citado).

38 Véase Convention on Cybercrime, ETS núm. 185, hecha en Budapest el 23 de noviembre de 2001, ratificada masivamente por los Estados miembros, con las excepciones, en lo que hace a miembros de la UE, de Grecia, Irlanda y Suecia, pero con la participación de terceros Estados no miembros del CoE como Australia, Canadá, República Dominicana, Israel, Japón, Mauricio, Panamá, Sri Lanka y Estados Unidos.

39 Véase Protocolo Adicional al referido Convenio contra la Cibercriminalidad (ETS núm. 189), hecho en Estrasburgo el 28 de enero de 2003, en el que hay bastantes más ausencias de Estados miembros del CoE y de la UE, destacando al respecto, por los recientes y graves atentados sufridos y por la radicalización que los mismos han puesto de manifiesto en ciertas áreas metropolitanas, la falta de ratificación de Bélgica, pero también de Grecia, Hungría, Italia, Irlanda, Suecia o el Reino Unido.

${ }^{40}$ Como fue notablemente el caso del atentado en Oslo y la matanza de jóvenes en Utoya en 2011. 
entender la religión islámica — véanse si no los atentados contra la revista Charlie Hebdo, de 7 de enero de 2015-, y la vocación de radicalización que persigue la suma de adeptos a la causa no deja de basarse en el odio a personas o colectivos por las razones expuestas en el Convenio de Budapest, como lo demuestra, entre otros, el ataque en el museo judío de Bruselas de 24 de mayo de 2014, o el ataque al supermercado kosher en París el 9 de enero de $2015^{41}$.

\section{LA RELATIVA/ABSOLUTA ESTERILIDAD DEL RECURSO SISTEMÁTICO DE LOS ESTADOS A LA FUERZA Y SUS CONSECUENCIAS EN LOS PILARES BÁSICOS DEL DERECHO INTERNACIONAL}

De acuerdo con todos los precedentes hasta aquí acumulados en relación con los ataques terroristas de nuevo cuño, la opción al parecer preferida por los Estados a la hora de combatir el terrorismo internacional, incluido el caso sin duda peculiar del Daesh, es el recurso sistemático al uso de la fuerza. Y ello con todo lo que tal respuesta implica, como es bien sabido.

En primer lugar, la atribución de responsabilidad internacional a actores no estatales considerados sujetos de la conducta ilícita que motiva el uso de la fuerza defensiva, y que difícilmente encajan ni en el esquema de responsabilidad internacional pergeñado en el proyecto de artículos de la CDI ${ }^{42}$, ni en la jurisprudencia de la $\mathrm{CIJ}^{43}$. A pesar de su impugnación de facto por algunos Estados este proyecto constituye, quiérase o no, la única directriz existente en el Derecho internacional contemporáneo tanto para los Estados

41 En este sentido el TEDH ha tenido ya ocasión de pronunciarse en diversas ocasiones sobre los límites a la libertad de expresión cuando esta puede devenir en lo que ha dado en llamarse el «discurso del odio» o la incitación al odio, al racismo y a la discriminación, y ha desechado directamente como incompatible con las bases mismas del CEDH un gobierno basado en la sharia. Véase asunto Kasymakhunov and Saybatalov v. Russia, Application nos. 26261/05 and 26377/06, de 14 de marzo de 2013.

42 Véase la imposible aplicación ni del art. 8 del Proyecto de artículos de la CDI en la materia, relativo al comportamiento de individuos o grupos que actúan de facto en nombre del Estado, bajo la dirección o control de este; ni del art. 9 del mismo Proyecto, relativo al comportamiento en caso de ausencia o defecto de las autoridades oficiales, pues aunque pudiera llegar a aceptarse que se trate de un grupo de personas que ejerce de hecho funciones de poder público, por ser un territorio fuera de control por parte del Estado territorial como consecuencia del existente conflicto armado interno, ello equivaldría en la práctica a aceptar la consolidación de situaciones territoriales alcanzadas mediante el uso de la fuerza armada, al constituir el Daesh en todo caso una de las partes opuestas en el conflicto, aunque se procede a hacer una diferencia aclaratoria de forma sistemática por razones evidentes, entre la oposición al régimen sirio surgida al calor de los hechos que motivaron la represión de este gobierno que genera dicho conflicto interno y el Daesh, como organización terrorista; y además porque en ningún caso podría entenderse que la actuación del Daesh se produzca en circunstancias tales que requieran el ejercicio de esas atribuciones; y por último porque, como se ha dicho anteriormente, el Daesh no ha pretendido en ningún momento presentarse como un movimiento de liberación nacional, pese a la utilización en la proclamación del califato del argumento de la denuncia de los acuerdos Sykes-Picott.

43 Véanse las afirmaciones claras y contundentes de la CIJ tanto en el asunto contencioso de las actividades militares y paramilitares en y contra Nicaragua, ICJ Reports, 1986, parr. 195, como en la opinión consultiva respecto de la construcción de un muro en los territorios palestinos ocupados, ICJ Reports, 2004, parrs. 139 y 142, entre otros asuntos. 
como para los órganos de dicho ordenamiento encargados de decidir sobre la concurrencia de dicha responsabilidad internacional. Y esta respuesta armada supuestamente "defensiva», en la medida en que obliga a interpretaciones «anti-natura» de las disposiciones correspondientes a la atribución de la conducta en cuestión que se encuentra en la base del ilícito internacional que legitima finalmente el uso de la fuerza ${ }^{44}$, no supone sino un retroceso ${ }^{45} \mathrm{y}$ un recurso a contramedidas o represalias consistentes en el uso de la fuerza armada prohibidas por el Derecho internacional ${ }^{46}$.

Y es que, en segundo lugar, seguimos asistiendo a una interpretación aberrante del concepto de legítima defensa, hecho que resulta particularmente

$44 \mathrm{Y}$ que, conforme a la interpretación hasta aquí aceptada del art. 51 de la CNU, han de provenir de un ejército regular de un Estado o de un grupo que un Estado de forma oficiosa envía a actuar contra otro o de alguna manera controla (art. 8 del Proyecto de artículos de la CDI sobre la Responsabilidad del Estado por hechos internacionalmente ilícitos, Doc. UN A/56/10), siendo posible considerar todo aquello que exceda de esa definición como un acto de agresión armada prohibido por el ordenamiento internacional, conforme a la definición del crimen de agresión acordada en la Resolución de la AGNU 3314 (XXIX), de 14 de diciembre de 1974, sobre la definición de la agresión, art. 3.

45 Véanse CARrillo SAlcedo, J. A. y Frowein, E., Les aspects juridiques du terrorisme international The Legal Aspects of International Terrorism, Dordrecht, Maritnus Nijhoff Publishers, 1989, pp. 55-96; Remiro Brotons, op. cit., nota 6, p. 157; Alcaide FernándeZ, op. cit., nota 22, p. 300; CASSESE, A., «Terrorism is Also a Disrupting some Crucial Legal Categories of International Law», EJIL, 2001, pp. 9931001, en particular véanse pp. 994-995; GonZÁlez VEGA, J., "Los atentados del 11 de septiembre, la operación "Libertad Duradera” y el derecho de legítima defensa», REDI, 2001, núms. 1 y 2, pp. 247 y ss.; GutiÉRrez EsPADA, C., "Algunas reflexiones en torno a la legítima defensa», en La responsabilidad internacional. Aspectos de Derecho internacional público y Derecho internacional privado. XIII Jornadas de la Asociación Española de Profesores de Derecho Internacional y Relaciones Internacionales, Alicante, 1990, pp. 292 y ss. Sorprende en este sentido la resolución del IDI 10A, de 27 de octubre de 2007, adoptada en la sesión de Santiago de Chile, relativa a "Present Problems of the Use of Armed Force in international Law. A Self-defence», cuando, pese a recordar en su punto 6 que "There is no basis in international law for the doctrines of "preventive" self-defence», sin embargo, afirma previamente de forma más que ambigua en su punto 3 que: "The right of self-defence arises for the target State in case of an actual or manifestly imminent armed attack [...]», continuando en su punto 5 con los requisitos para dicha posible acción en legítima defensa, además de la necesidad y proporcionalidad exigidas por la Carta: "An armed attack triggering the right of self-defence must be of a certain degree of gravity». Y lo deja aún más claro cuando en su parte final se centra en los posibles ataques perpetrados por parte de actores no estatales, afirmando rotundamente que: "In the event of an armed attack against a State by non-State actors, Article 51 of the Charter as supplemented by customary international law applies as a matter of principle [...] ii. If an armed attack by non-State actors is launched from an area beyond the jurisdiction of any State, the target State may exercise its right of self-defence in that area against those nonState actors». Pero eso es decir mucho, pues en nuestra opinión no podría entenderse que estamos, en el actual conflicto con el Daesh, ante un caso de uso de la fuerza contra un non-state actor cuyo territorio se encuentra más allá de la jurisdicción de un Estado, salvo que decidamos aceptar que la situación de pérdida de control sobre un porción de su territorio por parte de un Estado como resultado del uso ilegal de la fuerza armada permite la consolidación del mismo a favor de dicho actor no estatal, esto es, dando al traste no solo con los conceptos de legítima defensa y sistema de seguridad colectiva, sino los principios básicos sobre los que se fundamenta el actual orden jurídico internacional y con la norma de ius cogens que prohíbe el uso de la fuerza con carácter absoluto y cuya única excepción, la legítima defensa, debe quedar sometida a interpretación restrictiva.

46 Véase Remiro Brotons, op. cit., nota 5, pp. 157-158; Rodríguez CARrión, A., «El elemento objetivo de la responsabilidad internacional por la violación de la obligación de abstenerse de recurrir a la fuerza», en La responsabilidad internacional, Aspectos de Derecho internacional público y Derecho internacional privado. XIII Jornadas de la Asociación Española de Profesores de Derecho Internacional y Relaciones Internacionales, Alicante, 1990, p. 279; CONDORELLI, L., "Les attentats du 11 septembre et leur suites. Où va le Droit international?», RGDIP, 2001, p. 840. 
llamativo en el caso del Daesh que, a diferencia de Al Qaeda - de la que se presumía disfrutar de un apoyo del régimen talibán (en todo caso ilegal y prácticamente no reconocido) como gobierno de un país que, por derivación, amparaba y respaldaba a una organización terrorista - esta es una organización terrorista que controla un territorio que afecta a dos Estados. Ahora bien, solo uno de ellos ha solicitado formalmente auxilio de otros Estados a fin de eliminar de su territorio dicho grupo terrorista y recuperar su integridad territorial, constituyendo este el origen de la conocida coalición internacional que bombardea la zona ${ }^{47}$. El otro Estado, sin embargo, se encuentra sumido en un conflicto armado interno, y si bien se ha sospechado si no su colaboración, sí cierta aquiescencia inicial a las acciones desarrolladas en una parte de su territorio por parte del Daesh, se trata en de un territorio que en todo caso no controlaba como consecuencia de dicho conflicto armado interno, y sobre el que no ha autorizado uso alguno de la fuerza, ni el Consejo de Seguridad ha logrado un acuerdo. Al contrario, su reacción se ha limitado a invitar a un Estado en concreto a venir en su auxilio y a contribuir con sus fuerzas armadas a la defensa de su territorio ${ }^{48}$. Lo que es válido para Irak desde el punto de vista del Derecho internacional ha de serlo —nos guste más o menos- también para Siria.

Sin embargo, el CSNU ha cedido a la presión de la coalición internacional para, en una resolución diplomática y calculadamente ambigua, sin mencionar expresamente la autorización del uso de la fuerza con base en el capítulo VII de la Carta, permitir la intervención armada también en el territorio sirio como consecuencia de la importancia de la amenaza que Daesh supone para la comunidad internacional. $\mathrm{Y}$ en ambos casos se ha recurrido abusivamente al concepto de legítima defensa, única justificación legal posible del uso de la fuerza conforme a la CNU, que ha sido utilizado tanto por la coalición internacional en un supuesto ejercicio colectivo de legítima defensa, como por parte de Estados individualmente — con especial significación Francia en sus

47 De conformidad con lo establecido en el art. 51 de la CNU y el art. 21 del proyecto de artículos de la CDI, y recordado en el punto 8 de la citada Resolución del IDI 10A de 2007. La llamada coalición internacional contra el Daesh está formada por 63 países, entre ellos, España, y liderada por Estados Unidos, cuyo Congreso aprobó el 19 de septiembre de 2014 la propuesta del presidente Obama de armar al ejército sirio, iniciando así la implicación de este Estado en el conflicto sirio, así como de bombardear al Daesh, responsable en los días inmediatamente anteriores de la decapitación de dos periodistas de nacionalidad norteamericana y de un británico. Las acciones armadas no se limitaron solo a territorio iraquí, sino que cubrieron igualmente territorio sirio bajo control del Daesh, al margen de cualquier pronunciamiento por parte del CSNU, simplemente soportada por el gobierno de Bashar Al Asad y bajo estricto control ruso, hasta que finalmente la Federación Rusa decidió, a petición del gobierno sirio, entrar también en el conflicto, bombardeando junto al ejército sirio posiciones básicamente de la oposición al régimen de Al Asad, no tanto del Daesh, iniciándose dichas acciones el 6 de octubre de 2015, Así se consagraba el papel del Consejo de Seguridad de convidado de piedra, que solo en diciembre de 2015, y sin hacer mención al capítulo VII de la CNU, condonó a posteriori los bombardeos en curso sobre territorio sirio, de dudosa o nula legalidad, mediante un llamamiento a la cooperación internacional para acabar con la amenaza que la consolidación y acción del Daesh en territorio iraquí y sirio supone para el conjunto de la Comunidad internacional. Véase la Resolución del CSNU S/RES/2249 (2015), de 20 de noviembre.

${ }_{48}$ Tal y como recuerda el punto 8 de la citada Resolución 10A del IDI de 2007. 
bombardeos de septiembre de 2015-, alegando que el territorio sirio controlado por el Daesh sirve de base para preparar atentados, y haciendo por este medio y de forma indirecta al Estado sirio responsable de los mismos. Este argumento es equivalente al utilizado contra Al Qaeda en su momento, pero con un pequeño matiz: la existencia de un conflicto armado en ese territorio y la falta de control por parte del Estado territorial de dicho espacio geográfico, que le pertenece.

Pero además, el efecto colateral de dicho abuso no es otro que el debilitamiento del ya maltrecho sistema de seguridad colectiva establecido en la Carta y su deslegitimación ${ }^{49}$, así como un nuevo retroceso que nos devuelve a las discusiones habidas en su momento respecto de la respuesta armada ofrecida por la coalición internacional del momento -Estados Unidos, Reino Unido y España- en 2001 y 2003, y que reaparecen como fantasmas tras los recientes ataques de París, cuando el primer ministro francés y el propio presidente de la República no dudaron - al más puro estilo George W. Bush - en declarar la existencia de un estado de guerra contra el terrorismo internacional ${ }^{50}$, un desafortunado y pernicioso dejà vu que no solo no hace precisamente avanzar al Derecho internacional, sino que ofrece argumentos a la propaganda terrorista y ayuda a su causa del reclutamiento de afines.

\section{4. ¿AL RESCATE DE PROPUESTAS DEL PASADO O DE OPORTUNIDADES PERDIDAS?}

El 30 de septiembre de 2015 el gobierno español junto con el gobierno rumano, presentaban a un grupo de Estados, en la sede de la representación permanente del primero ante las Naciones Unidas en Nueva York, un incipiente proyecto para su discusión antes de su presentación oficial ante el CSNU prevista para el otoño de 2016 sobre la creación de una Corte Internacional para enjuiciar crímenes de terrorismo ${ }^{51}$.

El objetivo, conforme a esta iniciativa conjunta rumano-española, sería acabar con la impunidad de aquellos individuos que cometen crímenes de terrorismo internacional mediante la creación de un Tribunal Internacional contra el Terrorismo, cuya competencia seria, al igual que la Corte Penal Internacional (CPI), complementaria de las jurisdicciones nacionales. Se concebiría, pues, como un tribunal encargado de juzgar dichos crímenes cuando los Estados no quieran o no puedan - «unable or unwilling», términos amplios e indefinidos bien conocidos ya en la teoría y en la práctica forense del

\footnotetext{
49 Véase por todos Remiro BRotons, op. cit., nota 5, p. 155.

50 Véanse declaraciones en http://www.elmundo.es/internacional/2015/11/14/5647073022601d152e $8 b 45 f e . h t m l$ (última consulta 20 de julio de 2016).

51 Un tribunal internacional para el terrorismo: España y Rumania. Véase, en el caso de España, http://www.exteriores.gob.es/Portal/es/SalaDePrensa/ElMinisterioInforma/Paginas/Noticias/20150930_ MINISTERIO3.aspx (última consulta 5 de julio de 2016); y por parte de Rumanía: https://www.mae.ro/ en/node/31628 (última consulta 5 de julio de 2016).
} 
Derecho internacional, tanto histórico como contemporáneo- proceder a su enjuiciamiento. Esto es, un tribunal internacional en principio de ámbito universal pero especializado en un solo crimen, el terrorismo internacional, y establecido mediante resolución del CSNU, a semejanza de los tribunales penales ad hoc ya establecidos con anterioridad como los clásicos de la antigua Yugoslavia y Ruanda ${ }^{52}$.

Esta propuesta plantea no pocos interrogantes. Uno, sin duda, sería su competencia ratione materiae, dada la inexistencia de una definición consensuada de terrorismo a nivel internacional, como se ha puesto de manifiesto con anterioridad, y la inadecuación de la técnica del listing, usada en los convenios internacionales, para una tipificación penal semejante, aún más tratándose del único delito/crimen competencia de este nuevo Tribunal, conforme a lo establecido en esta propuesta preliminar. Y ello, entre otras razones, porque ese listado cambia conforme el fenómeno terrorista lo hace. Baste recordar de nuevo la reciente tipificación convencional del adiestramiento pasivo o del desplazamiento a fin de colaborar de alguna manera con una organización terrorista, aparecidos como consecuencia del alarmante reclutamiento masivo de terroristas combatientes extranjeros. A ello deben añadirse las nuevas preocupaciones que no constituían, en el momento de su adopción, objeto de atención por parte de los instrumentos convencionales que luchan contra la cibercriminalidad, en un principio preocupados por el uso de la TICs a fines de atacar infraestructuras críticas del Estado, o a efectos de realizar transacciones financieras que de alguna manera sirvieran de soporte para organizaciones terroristas ${ }^{53}$. Sin haber decaído dichas preocupaciones, a estas se han añadido otras nuevas tales como el uso de las redes sociales con fines de radicalización o el almacenamiento de datos en la nube (icloud), que se han convertido en una prioridad ${ }^{54}$. Sería difícil concebir un Estatuto de un Tribunal internacional creado mediante una resolución del CSNU cuya competencia tuviese que ser enmendada periódicamente conforme el listado de conductas se actualizase, se entiende que mediante la adopción de una nueva resolución de dicho órgano al efecto.

La falta de definición que sustenta su tipificación ya de entrada parece un obstáculo importante. Ello sin mencionar los inconvenientes que su creación puede plantear si esta se materializa por medio de la adopción de una resolución del CSNU, y que ya se discutieron con ocasión de la creación de los mencionados tribunales penales ad hoc, razón por la cual esta vía no

52 En el caso de la antigua Yugoslavia véase Resolución estableciendo «un Tribunal Penal Internacional para el procesamiento de las personas responsables de las serias violaciones de Derecho internacional humanitario cometidas en el territorio de la ex-Yugoslavia desde 1991", S/RES/808 (1993), de 22 de febrero de 1993; y en el caso de Ruanda véase Resolución CSNU S/RES/ 955 (1994), de 8 de noviembre, del Consejo de Seguridad de las Naciones Unidas, por la que se crea un Tribunal Internacional para el enjuiciamiento de los crímenes internacionales perpetrados en Ruanda.

53 Véase Council of Europe, Cyberterrorism: the use of the internet for terrorist purposes, Estrasburgo, 2008, informe preliminar.

54 Véase Criminal Justice Access to Date in the Cloud: challenges, en http://www.coe.int/en/web/ cybercrime (última consulta 15 de julio de 2016). 
parece ser la forma más adecuada para su puesta en funcionamiento. Ello es así en particular si lo que se pretende es el respaldo de un gran consenso de la comunidad internacional, dado el carácter eminentemente restringido del órgano que lo crearía y de la necesidad de que este ejerciera de nuevo una competencia cuasi legislativa, con las críticas que ello ha supuesto ya en relación a otras actuaciones de tipo normativo del CSNU ${ }^{55}$.

En todo caso, y frente a la lenta "cochura» de un instrumento internacional convencional que, además, podría ser personalizado por los Estados por medio de declaraciones o reservas, y que solo podría enjuiciar situaciones que tengan lugar una vez entrado este en vigor, una resolución del CSNU tendría la virtualidad de establecer una competencia de carácter retroactivo que permitiese el enjuiciamiento de actos terroristas cometidos con anterioridad, como ya ha sido el caso. Esto es, existirían también interrogantes respecto de la competencia ratione temporis de este nuevo Tribunal. En este sentido, la propuesta hispano-rumana parece decantarse por una insólita fórmula intermedia o híbrido, que supondría la adopción de una resolución del CSNU creando dicho tribunal con una duración máxima de 10 años, plazo durante el cual los Estados se comprometerían a abrir a la firma dicho Estatuto transformándolo en una convención internacional posteriormente ${ }^{56}$.

Por otro lado, la tipificación del crimen de terrorismo, objeto único de la competencia de tal Tribunal, exigiría la delimitación de sus elementos, algo que en principio, y en caso de actos terroristas cometidos en el marco de un conflicto armado, ya encontrarían acomodo en el DIH mediante los tipos penales de crimen de guerra o, en su caso, crimen de lesa humanidad ${ }^{57}$, quedando además incorporados automáticamente en la competencia de la ya existente $\mathrm{CPI}^{58}$. Por tanto habría que entender que este nuevo Tribunal internacional tendría únicamente competencia para conocer de acciones o conductas tipificadas en su estatuto como crimen de terrorismo cometidas en tiempos de paz y no en el marco de un conflicto armado, por innecesario en el segundo

55 Véase Arangio Ruiz, G., «On the Security Council’s “Law Making”, RDI, 2000, pp. 609-725; GutiérREZ EsPaDA, C., «No cesaréis de citarnos leyes viendo que ceñimos la espada? (a propósito del 11-S», $A D I, 2001$, p. 29; ANDrés SÁEnz de Santa María, P., «El Consejo de Seguridad en la guerra contra Irak ¿ONG privilegiada, convalidador complaciente u órgano primordial?», REDI, 2003, núm. 1, pp. 205-222.

56 La propuesta, que aún no ha sido oficialmente presentada, ha sido expuesta en el Club de Madrid por el Ministro de Asuntos Exteriores de Rumanía. Véase https://www.mae.ro/en/node/34450 (última consulta 10 de julio de 2016).

57 Los Convenios de Ginebra reaccionan ante los actos de terrorismo en dos situaciones diferentes. En el caso de los conflictos armados internacionales, el art. 33 del IV Convenio y en particular el art. 51.2 del Protocolo I, prohíbe los ataques contra la población civil, los actos o amenazas de violencia cuya finalidad principal sea aterrorizar a la población civil, prohibiéndose en el art. 37 del mismo los llamados actos de perfidia, de los que el Daesh ha dado hasta aquí buena muestra. Y por lo que hace a los conflictos armados de carácter no internacional, dicha prohibición se provee además, como se sabe, en el art. 3 común a los cuatro Convenios, en el art. 13.2 se prohíben los actos o amenazas contra la población civil a fin de aterrorizarla, en los mismos términos, pues, que lo hace el art. 51 del Protocolo I en relación a los conflictos armados internacionales. Véase al respecto GASSER, H. P., «Actos de terror, terrorismo y derecho internacional humanitario», Revista Internacional de la Cruz Roja, 2002, p. 1-18.

58 Véanse arts. 7 y 8 del Estatuto de la CPI. 
caso. Tampoco queda claro si su competencia debería también extenderse a actos terroristas cometidos por las fuerzas armadas de un Estado, o lo que es lo mismo, penalizar también el denominado «terrorismo de Estado».

Ahora bien, y como se ha apuntado ${ }^{59}$, limitar la competencia del nuevo Tribunal a actos terroristas perpetrados solo en tiempos de paz podría dificultar el tratamiento de determinadas situaciones conflictivas cuya naturaleza no queda clara desde el punto de vista jurídico y que ha dado pie a algunas situaciones problemáticas con las que han debido tratar, por ejemplo, las instituciones de la UE, tales como los Tigres para la Liberación del Eelam Tamil ${ }^{60}$; o el caso contra Hamás, pendiente de recurso ante el TJUE ${ }^{61}$. Pero además, Estados Unidos o Francia se han declarado en guerra, esto es, envueltos en un conflicto armado, contra organizaciones terroristas, por lo que en principio estas situaciones estarían excluidas de la competencia de semejante Tribunal.

Por último surge la duda sobre si, en aquellos casos en los que la CPI fuese competente conforme a su Estatuto, pero sin embargo decidiera finalmente no ejercer jurisdicción, este nuevo Tribunal sí podría intervenir, dando lugar a un cierto fórum-shopping por parte del Estado denunciante o del propio CSNU, mermando significativamente la competencia del nuevo Tribunal. Además, la propuesta incluye la creación de una fuerza multinacional de policía como único mecanismo de acompañamiento para la aplicación y cumplimiento efectivo de las decisiones de dicho Tribunal, un aspecto este que tan en evidencia ha puesto a la CPI, entre otros ejemplos, en el asunto $\mathrm{Al}$ Bashir.

En cualquier caso la propuesta no deja de merecer al menos la valoración positiva de afrontar la acción contra el terrorismo internacional desde el ámbito del Derecho y no desde el uso de la fuerza, aunque habría que esperar en todo caso a ver la relación que se pudiera establecer entre esta y el CSNU en la medida en que, como ya se ha expuesto, este viene situando de forma sistemática desde hace ya dos décadas la acción contra el terrorismo bajo el Capítulo VII de la Carta, de su competencia exclusiva, y sin hacer distingos entre actos terroristas en relación a situaciones de conflicto armado o en tiempos de paz. Tampoco puede obviarse la apreciación de que, en todo caso, se trataría de la creación de una jurisdicción internacional de excepción que extrae un crimen internacional como el terrorismo de la jurisdicción inter-

59 Véase Pantaleo, L. y RibBelinK, O., «The Establishment of a Spcial Court against Terrorism», en http://www.ejiltalk.org/the-establishment-of-a-special-court-against-terrorism/ (última consulta 19 junio de 2016).

60 Véase sentencia en los asuntos acumulados T-208/11 y T-508/11, Liberation Tigers of Tamil Eelam (LTTE)/Consejo, de 16 de octubre de 2014, en los que el Tribunal anula por motivos de procedimiento los actos del Consejo por los que se mantiene a los Tigres para la Liberación de la Patria Tamil en la lista europea de organizaciones terroristas.

61 Debe recordarse igualmente la causa pendiente a día de hoy ante el TJUE respecto de la decisión del TGUE de anular la inclusión de Hamás como organización terrorista en dicha lista por defectos de procedimiento (caso Council/Hamás de 17 de diciembre de 2014, T-400/10), decisión judicial que ha sido recurrida por el Consejo ante el TJUE y se encuentra aún pendiente de resolución, plazo durante el cual Hamás permanecerá incluida en la lista. 
nacional existente que a nuestro juicio debiera ser la instancia natural para conocer de dichos supuestos, de forma complementaria o subsidiariamente a la competencia de las jurisdicciones nacionales. Hasta ahora, todo intento de crear jurisdicciones especiales en materia de terrorismo no ha producido los mejores resultados: ni los tribunales inicialmente solo militares y luego mixtos utilizados en Turquía y condenados por el TEDH, entre otros intentos, ni las comisiones militares en el caso de los detenidos en la base de Guantánamo. Y es que sobre dichas propuestas suele planear el sesgo político que inevitablemente el terrorismo conlleva y la tentación de que tales tribunales de excepción acaben tachando de terroristas conductas que no lo sean de forma clara y evidente. Como la Comisión Internacional de Juristas tuvo ocasión de afirmar de forma contundente, la tentación de configurar al terrorismo como un crimen no común, y por tanto sometido a un tribunal de excepción o especial, puede acabar en los peores abusos, y en consecuencia su recomendación de someter al terrorismo a los tribunales penales ordinarios, ya sean nacionales o internacionales ${ }^{62}$.

Todo lo anteriormente expuesto nos lleva a insistir en la necesidad de recordar la que debiera haber sido la primera opción: la inclusión del terrorismo como crimen de la competencia de la CPI en el momento de acordar el Estatuto de Roma, lo que se desechó como consecuencia básicamente de la falta de consenso respecto de la definición de terrorismo, necesaria para su tipificación en el Estatuto ${ }^{63}$, y que fue aplazada, en su caso, a una futura revisión del mismo ${ }^{64}$. La CPI, creada en el año 2000 tras la recepción de las sesenta ratificaciones requeridas, fue testigo de los ataques terroristas del 11/S, aunque los detractores de la misma, principales afectados por estos, probablemente no lamentaron esta ausencia, pues su principal obsesión fue la detención por cualquier medio posible de los sospechosos y la sujeción de los detenidos a una jurisdicción propia de excepción.

La inclusión del terrorismo como crimen de la competencia de la CPI sería, por tanto, la opción más adecuada, en caso de Estados incapaces o no deseosos de afrontar el enjuiciamiento ante sus propios tribunales de los posibles responsables de tales actos, constituyendo en este sentido la CPI el tribunal penal natural — si bien de alcance universal - y ordinario - como jurisdicción competente para una serie de delitos-, para juzgar los más graves crímenes contra la comunidad internacional en su conjunto, incluido el terrorismo.

62 Véase International Commission of Jurists: Assessing damage, urging action. Report of the Eminent Jurists Panel on Terrorism, Counter-terrorism and Human Rights, Ginebra, 2009.

63 Si bien inicialmente se contemplaba la inclusión del terrorismo como uno de los crímenes de la competencia de la Corte, por influencia del Código de crímenes contra la paz y la seguridad de la humanidad elaborado por la CDI (A/CONF.183/2/Add.1, pp. 27-28), sin embargo, finalmente fue descartada su inclusión como consecuencia principalmente de la falta de consenso respecto de su definición.

${ }_{64}$ Merced a la voluntad de las delegaciones de Argelia, India, Sri Lanka y Turquía, que forzaron la adopción de la Resolución E, incluida en el Acta Final de la Conferencia de Roma, que preveía la reconsideración de la inclusión de dicho crimen en la futura conferencia de revisión del estatuto, calificando a los crímenes de terrorismo como graves crímenes de trascendencia para la comunidad internacional. 


\section{EL VALOR AÑADIDO DE LA APROXIMACIÓN DESDE LA COOPERACIÓN PENAL INTERNACIONAL}

Como la realidad se ha encargado de demostrar y NU ha defendido ${ }^{65}$, una lucha eficaz y total contra el terrorismo no se puede lograr solo con la implementación de los convenios específicos sobre lucha contra el terrorismo, ya sean universales o regionales, sino que el refuerzo de la cooperación judicial en materia penal constituye también una pieza clave. En este sentido Europa no deja de ser un área privilegiada tanto por los convenios adoptados en el seno del CoE, como por la acción normativa de la UE.

En primer lugar, en rápida respuesta a la solicitud formulada en la Resolución CSNU 2178, el Consejo de Europa adoptó de un Protocolo Adicional al Convenio sobre Prevención del terrorismo de 2005, que define y exige de los Estados partes la tipificación penal a nivel nacional de una nueva serie de actos preparatorios, tales como: a) el adiestramiento o entrenamiento pasivo $^{66}$, que guarda relación directa con el alarmantemente creciente fenómeno del auto adiestramiento o self-radicalisation, mediante el uso de Internet y de las redes sociales; $b$ ) el desplazamiento de personas con el objetivo claro de interactuar en la medida que sea con organizaciones terroristas, bien sea cometer atentados terroristas, contribuir a ellos, participar en ellos, ofrecer o recibir entrenamiento terrorista, siempre en el caso de viajes a países de los cuales la persona concernida no sea nacional ni tenga en él su residencia ${ }^{67} \mathrm{e}$ independientemente de dónde geográficamente inicien su viaje ${ }^{68} ; c$ ) así como financiar tales viajes total o parcialmente, de forma directa o indirecta, o contribuir a la recaudación de fondos a tales efectos ${ }^{69}$.

Y a pesar de la polémica que su adopción pueda haber despertado a nivel internacional, en particular por la colisión que podría suceder en la práctica entre la figura del autoadiestramiento y la libertad de expresión y/o información, así como la libertad ambulatoria en lo que concierne a los desplazamientos de los potenciales combatientes terroristas extranjeros ${ }^{70}$, lo cierto es que no se trata de instrumentos internacionales alejados de la lucha a pie de

65 Véase Informe del Secretario General de NU sobre la amenaza que plantea el EIIL (Daesh) para la paz y la seguridad internacionales y la gama de actividades que realizan las NU en apoyo de los Estados miembros para combatir la amenaza, S/2016/92, de 29 de enero de 2016, p. 21; Informe del Secretario General de NU sobre la amenaza que plantea el EIIL (Daesh) para la paz y la seguridad internacionales y la gama de actividades que realizan las NU en apoyo de los Estados miembros para combatir la amenaza, S/2016/501, de 31 de mayo de 2016.

${ }_{66}$ Véase Convenio ETS núm. 217, art. 3.

67 Véase ibid., art. 4.

68 Véase, entre otros ejemplos, el caso de una española detenida en Turquía con su hijo, desde donde se disponía a viajar para unirse al Estado Islámico, en http://politica.elpais.com/politica/2015/04/17/ actualidad/1429296361_933696.html.

69 Véase Convenio ETS núm. 217, op. cit., nota 59, art. 5.

70 Véase «Amnesty International/International Commission of Jurists, Preliminary public observations on the terms of reference to draft an Additional Protocol supplementing the Council of Europe Convention on the Prevention of Terrorism, de 6 de marzo de 2015, IOR 60/1172/2015», en https://www. amnesty.org/en/documents/ior60/1172/2015/en/ (consultado el 6 de junio de 2016). 
calle contra esta situación, sino muy por el contrario, de instrumentos que obligan a los Estados ratificantes a tipificar dichas conductas y a sancionarlas convenientemente en sus sistemas penales internos, lo que, en definitiva, ofrece a un juez o un magistrado la posibilidad de dictar una orden de detención, por ejemplo, contra una persona que se encuentra en un aeropuerto dispuesta a tomar un avión para unirse a las filas del Daesh ${ }^{71}$.

En cuanto a la UE cabe destacar las dos nuevas iniciativas legislativas adoptadas como consecuencia directa de los atentados terroristas perpetrados tanto en París como en Bruselas a lo largo de 2015 y 2016. En primer lugar, la Directiva PNR sobre el registro de pasajeros ${ }^{72}$, que establece una serie de medidas en relación con el uso que de los datos personales de los pasajeros se puede hacer y su tráfico, así como el tiempo máximo de conservación, estableciéndose que se almacenarán en principio solo por seis meses, tras los cuales se encriptarán y se mantendrán hasta cinco años, pero con un acceso muy restringido y bajo petición expresa e individualmente justificada. La Directiva obliga a cada Estado miembro a crear una unidad que recibirá obligatoriamente de las compañías aéreas, y en relación a los vuelos que entren a o salgan de la UE, los datos PNR de sus pasajeros; esto es, nombre, fechas de viaje, itinerario, información del billete, datos de contacto, agencia de viajes con la que se contrató, medio de pago utilizado, número de asiento, información sobre el equipaje facturado e incluso acompañantes ${ }^{73}$. La nueva normativa, en vigor desde mayo de 2016, insiste en el respeto de los derechos y libertades fundamentales establecidos en la CDFUE y en el $\mathrm{CEDH}$, y en su uso no discriminatorio en relación con un número amplio de elementos (raza, etnia, religión, creencias políticas, religiosas o sindicales, salud, vida u orientación sexual). Su aplicación es obligatoria respecto de los vuelos transcomunitarios, pero los Estados miembros pueden optar por su implementación voluntaria a los vuelos intra comunitarios, lo que de facto viene ocurriendo entre la mayoría de ellos desde hace ya tiempo.

La segunda iniciativa, aún en fase de proposición, corre paralela a la previsible entrada en vigor del nuevo Protocolo Adicional al Convenio de Prevención del Terrorismo del CoE sobre los combatientes ilegales, anteriormente mencionado ${ }^{74}$. La firma del Protocolo Adicional implica necesariamente la

${ }^{71}$ Como, por ejemplo, el caso de una española detenida en Barajas cuando se disponía a tomar un avión hasta Turquía para desde allí llegar a los territorios controlados por el Estado Islámico, en http://politica.elpais.com/politica/2015/10/20/actualidad/1445323600_402804.html (consultado el 10 de junio de 2016).

72 Una propuesta que había sido bloqueada tras el rechazo de la Comisión de Derechos y Libertades del Parlamento europeo. Ya el TJUE había declarado contraria a los tratados la Directiva 2004/24/CE sobre conservación de datos, en la sentencia dictada en los asuntos acumulados C-293/12 y C-594/12, Digital Rights Ireland y Seitlinger y otros, aunque en este caso se trataba de una Directiva más genérica.

73 Reino Unido e Irlanda se han comprometido con la misma, no así Dinamarca.

${ }^{74}$ En cuya votación en el seno del Comité de Ministros por primera vez en la historia la UE se pronunció y votó en nombre de sus 28 Estados miembros, firmando dicho instrumento en nombre de todos ellos, con los que previamente, y bajo presión británica, había aceptado el derecho de estos a utilizar la clausula de opting out. Véase Council Decision on the signing, on behalf of the European Union, of the Council of Europe Convention on the Prevention of Terrorism (CETS No. 196), Doc. JAI 595, 
aceptación del Convenio matriz también en nombre de la $\mathrm{UE}^{75}$, pues esta se siente obligada, como único medio de implementar el Protocolo Adicional en tanto que organización internacional ratificante, a incorporarlo a una norma propia, lo que justifica la propuesta de adopción de una Directiva al respecto $^{76}$.

No puede ignorarse que la propuesta de Directiva añade valor a lo ya regulado por el Protocolo Adicional, en la medida en que su contenido amplia ciertos aspectos como, por ejemplo, la inclusión de la ofensa de participar en actividades de un grupo terrorista; el robo agravado, la extorsión y el fraude con el propósito de cometer una ofensa terrorista; la protección de las víctimas; o la inclusión de ciertas circunstancias atenuantes para los colaboradores con la justicia en casos de terrorismo.

\section{ALGUNAS REFLEXIONES FINALES}

Si realmente los Estados tienen voluntad de luchar eficazmente contra esta nueva forma de terrorismo, además de seguir recurriendo de forma sistemática al uso de la fuerza, y los académicos reflexionando sobre su legalidad, ilegalidad, alcance y distorsiones que esta crea, y sobre la responsabilidad de los actores no gubernamentales de la llamada "guerra asimétrica» (cuando ya se había desterrado el término «guerra» como concepto no jurídico en el Derecho internacional contemporáneo), sería también importante seguir insistiendo en que los Estados se comprometan con otros instrumentos legales existentes a fin de favorecer la cooperación judicial internacional, y la criminalidad organizada transnacional, de manera que se combatan paralelamente todas las conductas que acompañan, protegen, financian o alimentan de alguna manera la acción de los grupos terroristas en cada uno de dichos ámbitos. Y es que, dada la inoperancia en muchos casos de los instrumentos universales de lucha contra el terrorismo, estos están necesitados sin duda de una adaptación y puesta al día.

Parece evidente que el reto actual del Derecho internacional es hallar medios idóneos para actuar contra un fenómeno criminal en mutación, con una concepción y medios de comisión diferentes que han convertido a este nuevo terrorismo, de falsa base religiosa e inexistente enfrentamiento cultural, en una ideología populista empleada de forma especialmente eficaz por lo que hoy día daría en llamarse una empresa de base tecnológica, el Daesh, y otras organizaciones afines para producir terror e imponer en este caso ideologías y formas de gobiernos contrarios a las más elementales normas del Estado de

DROIPEN 84, COPEN 214, ENFOPOL 220, COTER 111, Bruselas, 9 de septiembre de 2015, así como Doc. JAI 596, DROPEN 85, COPEN 215, ENFOPOL 221, COTER 112, Council Decision on the signing, on behalf of the European Union, of the Additional Protocol to the Council of Europe Convention on the Prevention of Terrorism (CETS N. 196), Bruselas, 9 de septiembre de 2015.

75 De acuerdo con el art. 10 del Protocolo Adicional.

76 Véase propuesta de Directiva, COM (2015) 625 final, de 2 de diciembre de 2015, pp. 5 y 6. 
Derecho, de los derechos humanos y de los principios esenciales del ordenamiento jurídico internacional.

\author{
RESUMEN \\ LUCHA CONTRA EL TERRORISMO INTERNACIONAL: \\ NO SOLO DEL USO DE LA FUERZA PUEDEN VIVIR LOS ESTADOS
}

La nueva dimensión que el terrorismo internacional ha adoptado desde los atentados del 11/S y en particular con la aparición del Daesh obliga al Derecho internacional a repensar sus instrumentos jurídicos a fin de optimizar su lucha contra esta lacra. A este respecto se analizan las aportaciones y carencias de los tratados de ámbito universal y su falta de adaptación a las actuales características del fenómeno terrorista en contraste con algunos instrumentos regionales en la materia. Tras la consideración de la dudosa eficacia del recurso sistemático a la fuerza por parte de los Estados y de las ventajas e inconvenientes de la creación de una jurisdicción internacional exclusivamente para juzgar acciones de terrorismo, se concluye apuntando hacia un mayor recurso a la cooperación penal internacional.

Palabras clave: Terrorismo, lucha contra el terrorismo internacional, yihadismo, cooperación penal internacional, Daesh, radicalización.

\title{
ABSTRACT \\ THE STATE FIGHT AGAINST INTERNATIONAL TERRORISM: BEYOND THE USE OF FORCE
}

The new dimension that international terrorism has attained after $\mathrm{S} / 11$ attacks in particular after the creation of the Daesh has obliged International Law to revisit its legal instruments in order to optimize the fight against this scourge. In this regard this contribution analyses advantages and shortages of universal treaties concerning the fight against terrorism and their problematic adaptation to this phenomenon's current features in clear contrast with some regional initiatives. After analyzing the dubious efficacy of States' systematic recourse to the use of force and the pros and cons of the creation of a new international court against terrorism, the study suggests a stronger use of the existing legal instruments for international cooperation on criminal matters.

Keywords: Terrorism, fight against international terrorism, jihadism, international cooperation on criminal matters, Daesh, radicalization. 